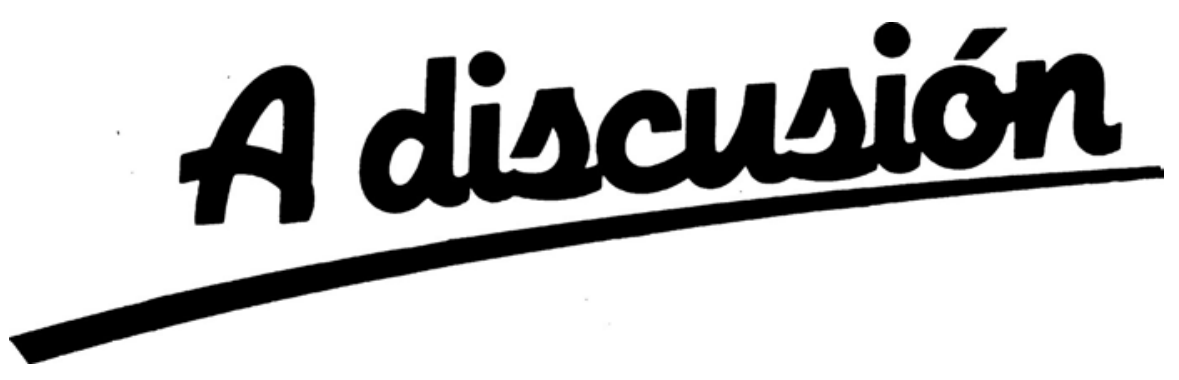

\title{
INCOME AND WEALTH DISTRIBUTIONS ALONG THE BUSINESS CYCLE: IMPLICATIONS FROM THE NEOCLASSICAL GROWTH MODEL*
}

\section{Lilia Maliar, Serguei Maliar and Juan Mora**}

WP-AD 2003-02

Correspondence L. Maliar: Universidad de Alicante, Departamento de Fundamentos del Análisis Económico, Campus San Vicente del Raspeig, Ap. Correos 99, 03080 Alicante (Spain), E-mail: maliarl@merlin.fae.ea.es.

Editor: Instituto Valenciano de Investigaciones Económicas, S.A.

Primera Edición Enero 2003

Depósito Legal: V-448-2003

IVIE working papers offer in advance the results of economic research under way in order to encourage a discussion process before sending them to scientific journals for their final publication.

* L. Maliar, S. Maliar y J. Mora: Universidad de Alicante.

** We have also benefited from comments of Jordi Caballe, Fabio Canova, Finn Kydland, Franck Portier, Morten Ravn, Michael Reiter, Xavier Sala-i-Martin, Alessandro Secchi, Andrew Scott and Chris Telmer. All errors are ours. 


\title{
INCOME AND WEALTH DISTRIBUTIONS ALONG THE BUSINESS GYGLE: IMPLICATIONS FROM THE NEOCLASSICAL GROWTH MODEL

\author{
Lilia Maliar, Serguei Maliar and Juan Mora
}

\begin{abstract}
This paper studies the business cycle dynamics of the income and wealth distributions in the context of the neoclassical growth model where agents are heterogeneous in initial wealth and non-acquired skills. Our economy admits a representative consumer which enables us to characterize the distributive dynamics by aggregate dynamics. We show that inequality in both wealth and income follows a counter-cyclical pattern: the former is counter-cyclical because of cyclical fluctuations in labor income, while the latter is counter-cyclical due to the wealth-distribution effect. We find that the predictions of the model about the income distribution dynamics accord well with the U.S. data.
\end{abstract}

Key words: Neoclassical growth model; heterogeneous agents; aggregation; business cycle; income and wealth distributions; inequality

JEL Classification: G68, D31, E32. 


\section{Introduction}

This paper examines the business cycle behavior of the income and wealth distributions in the context of the neoclassical growth model. To this purpose, we extend the benchmark neoclassical setup by Kydland and Prescott (1982) to include heterogeneous agents, who differ in initial wealth and nonacquired skills. Under the assumptions of complete markets and identical homothetic individual preferences, our economy admits a representative consumer in the sense of Gorman (1953), so that the income and wealth distributions are irrelevant for macroeconomic performance. In contrast, aggregate fluctuations fully determine the evolution of the income and wealth distributions over the business cycle. We therefore focus on the role of aggregate fluctuations in distributive dynamics. ${ }^{1}$

We show that, at any point in time, the income and wealth distributions in our economy can be represented as a linear combination of the skill distribution and the initial wealth distribution. During expansions, the weights of the skill distribution in the income and wealth distributions increase relative to the corresponding weights of the initial wealth distribution. During recessions, the reverse situation holds. The empirical evidence indicates that the skill differentials across agents are, on average, lower than the wealth differentials, which leads us to conclude that inequality in income and wealth is counter-cyclical. That is, expansions are equalizing, and recessions are disequalizing. ${ }^{2}$

In our economy, counter-cyclical behavior of wealth inequality can be understood by looking at how the wealth of different individuals is affected by the business cycle fluctuations of their labor income. A positive technology shock raises wages and working hours, thus increasing labor income. For "rich and low-productive" agents (i.e., those whose wealth share is high in relation to their skill share), labor income, however, is low in relation to wealth, so that its increase has little impact on wealth. In contrast, for "poor and highly-productive" agents, labor income constitutes a large fraction of wealth, so that its increase augments wealth considerably. As a result,

\footnotetext{
${ }^{1}$ Chatterjee (1994) and Caselli and Ventura (2000) also study the implications of a neoclassical model for income and wealth distributions employing the aggregation theory. These papers, however, concentrate on deterministic distributive dynamics over the process of economic development and neglect business cycle fluctuations.

${ }^{2}$ An extensive review of the literature on inequality can be found in the book edited by Atkinson and Bourguignon (2000).
} 
"rich and low-productive" agents decrease their wealth shares, and "poor and highly-productive" agents increase their wealth shares, and the inequality in wealth therefore decreases. With regard to a counter-cyclical behavior of income inequality, this is due to the wealth-distribution effect: a more equal distribution of wealth across agents leads to a more equal distribution of capital gains, thus reducing inequality in income. ${ }^{3}$

We test the model's predictions on the business cycle dynamics of the income distribution with U.S. data. We specifically study the time-series properties of the distance between income and skill distributions and between income and wealth distributions. We obtain that the former distance is counter-cyclical while the latter is pro-cyclical. We interpret these findings as evidence that supports the model's prediction that, during expansions, income distribution moves towards skill distribution and, during recessions, it moves towards wealth distribution. We also evaluate the explanatory power of the theoretical relation between the coefficient of variation of the income distribution and the corresponding aggregate variables. We find that the model can explain about $60 \%$ of the total variability seen in this coefficient.

The plan of the paper is as follows: Section 2 formulates the model and summarizes the aggregation results. Section 3 studies the model's distributional implications. Section 4 discusses the empirical results. Finally, Section 5 concludes.

\section{The model}

We consider a heterogeneous agents variant of the standard neoclassical stochastic growth model by Kydland and Prescott (1982). This variant of the model was first studied in Kydland (1984). Time is discrete and the horizon is infinite, $t \in T$, where $T=\{0,1, \ldots\}$. The economy consists of a representative production firm and a set of infinitely-lived agents $S$. The measure of an agent $s$ in the set $S$ is denoted by $d s$. The total measure of agents is one, $\int_{S} d s=1$. There is a complete set of markets, i.e., agents are permitted to trade state-contingent claims to next-period output.

\footnotetext{
${ }^{3}$ A related paper by Castañeda, Díaz-Giménez and Ríos-Rull (1998) studies the business cycle dynamics of income distribution in a neoclassical framework with incomplete markets, restrictions on borrowing and an indivisible labor choice. This paper advocates the importance of unemployment spells and cyclically-moving factor shares in explaining the dynamics of income inequality.
} 
The representative firm owns the production technology, which is given by a constant return-to-scale Cobb-Douglas function, $y_{t}=\theta_{t} k_{t}^{\alpha} h_{t}^{1-\alpha}$, where $y_{t}$ is output; $k_{t}$ and $h_{t}$ are the aggregate inputs of capital and labor, respectively; $\alpha \in(0,1)$; and $\theta_{t}$ is an exogenous technology shock. The shock follows a first-order Markov process with a transitional probability given by $\operatorname{Pr}\left\{\theta_{t+1}=\theta^{\prime} \mid \theta_{t}=\theta\right\}_{\theta^{\prime}, \theta \in \Theta}$, where $\Theta$ denotes the set of all the possible realizations of technology shocks. The profit-maximizing conditions of the firm imply that the real return on capital, $r_{t}$, and the real wage, $w_{t}$, are equal to the marginal products of capital and labor inputs, respectively, i.e., $r_{t}=\alpha \theta_{t} k_{t}^{\alpha-1} h_{t}^{1-\alpha}$ and $w_{t}=(1-\alpha) \theta_{t} k_{t}^{\alpha} h_{t}^{-\alpha}$.

The agents are heterogeneous in initial endowment and non-acquired skills. The skills of agent $s$ reflect the number of efficiency hours $e^{s}$ that correspond to one physical hour worked by the agent. Note that the individual skills are assumed to be constant over time and across states of nature. For the sake of convenience, we normalize the average level of skills to one, $\int_{S} e^{s} d s=1$.

The preferences of an agent $s$ are given by the expected discounted sum of the period utility functions. The period utility function is defined over consumption, $c_{t}^{s}$, and leisure, $l_{t}^{s}$, and is of the Constant Relative Risk Aversion (CRRA) type. The agent is endowed with one unit of time, so that $n_{t}^{s} \equiv 1-l_{t}^{s}$ represents her working hours. The problem solved by agent $s$ is as follows:

$$
\max _{\left\{c_{t}^{s}, n_{t}^{s}, k_{t+1}^{s}, m_{t+1}^{s}(\theta)\right\}_{\theta \in \Theta, t \in T}} E_{0}\left[\sum_{t=0}^{\infty} \delta^{t} \frac{\left(\left(c_{t}^{s}\right)^{\mu}\left(1-n_{t}^{s}\right)^{1-\mu}\right)^{1-\eta}-1}{1-\eta}\right]
$$

subject to

$$
c_{t}^{s}+k_{t+1}^{s}+\int_{\Theta} p_{t}(\theta) m_{t+1}^{s}(\theta) d \theta=\left(1-d+r_{t}\right) k_{t}^{s}+m_{t}^{s}\left(\theta_{t}\right)+n_{t}^{s} e^{s} w_{t},
$$

where the initial endowment $\left[\left(1-d+r_{0}\right) k_{0}^{s}+m_{0}^{s}\left(\theta_{0}\right)\right]>0$ is given. Here, $E_{t}$ denotes the conditional expectation; $k_{t+1}^{s}$ is the capital stock; $\left\{m_{t+1}^{s}(\theta)\right\}_{\theta \in \Theta}$ is the portfolio of state-contingent claims; $p_{t}(\theta)$ is the price of a claim that entitles the agent to the payment of one unit of consumption goods in period $t+1$ if state $\theta$ occurs; $d \in(0,1]$ is the depreciation rate of capital; $\delta \in(0,1)$ is the discount factor; and finally, $\mu \in(0,1)$ and $\eta>0$ are the parameters of the utility function.

We define an individual's wealth, $Z_{t}^{s}$, as the value of her end-of-period asset portfolio, expressed in terms of current consumption good, 


$$
Z_{t}^{s} \equiv k_{t+1}^{s}+\int_{\Theta} p_{t}(\theta) m_{t+1}^{s}(\theta) d \theta
$$

A competitive equilibrium is defined as a sequence of contingency plans for the consumers' allocation $\left\{c_{t}^{s}, n_{t}^{s}, Z_{t}^{s}\right\}_{t \in T}^{s \in S}$, for the allocation of the firm $\left\{k_{t}, h_{t}\right\}_{t \in T}$ and for the prices $\left\{r_{t}, w_{t}, p_{t}(\theta)\right\}_{\theta \in \Theta, t \in T}$ such that, given the prices, the sequence of plans for the consumers' allocation solves each agent's utility maximization problem (1), (2); the sequence of plans for the firm's allocation makes the rental price of each input equal to its marginal product; all markets clear:

$$
k_{t}=\int_{S} k_{t}^{s} d s, \quad h_{t}=\int_{S} n_{t}^{s} e^{s} d s, \quad \int_{S} m_{t+1}^{s}(\theta) d s=0
$$

and the economy's resource constraint is satisfied:

$$
c_{t}+k_{t+1}=(1-d) k_{t}+\theta_{t} k_{t}^{\alpha} h_{t}^{1-\alpha},
$$

where $c_{t} \equiv \int_{S} c_{t}^{s} d s$ is the aggregate consumption. Moreover, the equilibrium plans must be such that $c_{t}^{s} \geq 0$, and $n_{t}^{s} \in[0,1]$ for all $s, \theta, t$, and $w_{t}, r_{t}$, $k_{t} \geq 0$ for all $\theta, t$. We assume that equilibrium exists and that it is interior and unique.

If agents possess identical homothetic preferences and markets are complete, then there exists a representative consumer in the sense of Gorman (1953). The aggregation theory allows us to characterize the equilibrium in the heterogeneous agents economy in a simple way.

Proposition 1 For the economy (1) - (5), we have:

$i)$. The aggregate dynamics $\left\{c_{t}, h_{t}, k_{t+1}\right\}_{t \in T}$ are described by the representative consumer model,

$$
\max _{\left\{c_{t}, h_{t}, k_{t+1}\right\}_{t \in T}} E_{0}\left[\sum_{t=0}^{\infty} \delta^{t} \frac{\left(c_{t}^{\mu}\left(1-h_{t}\right)^{1-\mu}\right)^{1-\eta}-1}{1-\eta}\right] \quad \text { subject to }
$$

ii). Consumption and working hours of agents, $\left\{c_{t}^{s}, n_{t}^{s}\right\}_{t \in T}^{s \in S}$, satisfy

$$
c_{t}^{s}=c_{t} f^{s}, \quad n_{t}^{s}=1-\left(1-h_{t}\right) \frac{f^{s}}{e^{s}}
$$


where $\left\{f^{s}\right\}^{s \in S}$ is a set of positive numbers with $\int_{S} f^{s} d s=1 ;^{4}$ iii). Wealth of agents, $\left\{Z_{t}^{s}\right\}_{t \in T}^{s \in S}$, satisfies the recursive budget constraints,

$$
Z_{t}^{s}=E_{t}\left[\sum_{\tau=t+1}^{\infty} \delta^{\tau-t} \frac{u_{1}\left(c_{\tau}, h_{\tau}\right)}{u_{1}\left(c_{t}, h_{t}\right)}\left(c_{\tau}^{s}-n_{\tau}^{s} e^{s} w_{\tau}\right)\right]
$$

where $u_{1}\left(c_{\tau}, h_{\tau}\right) \equiv c_{\tau}^{\mu(1-\eta)-1}\left(1-h_{\tau}\right)^{(1-\mu)(1-\eta)}$.

Proof. See Maliar and Maliar (2001), Appendices A and B.

Consequently, to find equilibrium in the heterogeneous agents economy (1) - (5), we shall first solve for the aggregate quantities from the representative consumer model (6) and then restore the individual quantities by using $(7),(8)$. In the next section, we employ the representation $(6)-(8)$ to derive some useful analytical results regarding the evolution of the income and wealth distributions in the model.

\section{The model's distributional implications}

Before analyzing the model's distributional implications, we should highlight certain aspects of the data. We focus on the empirical facts of the income distribution dynamics because empirical evidence about the evolution of wealth distribution is rather scarce. We restrict our attention to distributional regularities observed in the U.S. economy because our subsequent empirical study is carried out using U.S. data.

Income inequality in the U.S. economy displays both long-run trend and short-run (business cycle) fluctuations. As regards long-run trend, income inequality falls during the first half of the 20th century but increases in 1970's and 1980's (see, e.g., Caselli and Ventura, 2000, Piketty and Saez, 2001). The business cycle behavior of the U.S. income inequality is documented by, e.g., Castañeda, Díaz-Giménez and Ríos-Rull (1998). Using the Current Population Survey data, they calculate the correlations between output and the income shares of different income groups. For the lowest three quintiles,

\footnotetext{
${ }^{4}$ The function $\left\{f^{s}\right\}^{s \in S}$ is related to the welfare weights $\left\{\lambda^{s}\right\}^{s \in S}$ in the associated planner's problem by $f^{s}=\frac{\left(\lambda^{s}\right)^{1 / \eta}\left(e^{s}\right)^{-\frac{(1-\mu)(1-\eta)}{\eta}}}{\int_{s \in S}\left(\lambda^{s}\right)^{1 / \eta}\left(e^{s}\right)^{-\frac{(1-\mu)(1-\eta)}{\eta}} d s}$.
} 
the income shares are pro-cyclical, and the correlation of the income share with output monotonically decreases from the first to the third quintile. For the forth quintile and for the next $15 \%$ of the population, the income shares are counter-cyclical. Finally, for the top 5\% income earners, the income share is acyclical. Similar regularities about the business cycle dynamics of the U.S. income quintiles are observed by Dimelis and Livada (1999) from the U.S. Current Population Report data. The latter paper also reports that the aggregate inequality measures of the U.S. income distribution such as the Gini and Theil coefficients are weakly counter-cyclical. ${ }^{5}$

Our model cannot explain long-run inequality trends observed in the data (it produces no such trends by construction). However, the model is capable of generating non-trivial dynamics of the income and wealth distributions over the business cycle. We therefore focus on the business cycle movements of these distributions.

We start by analyzing the model's implications for the wealth distribution dynamics. Consider the share of agent's $s$ wealth within the total wealth,

$$
z_{t}^{s} \equiv \frac{Z_{t}^{s}}{\int_{S} Z_{t}^{s} d s}=\frac{k_{t+1}^{s}+\int_{\Theta} p_{t}(\theta) m_{t+1}^{s}(\theta) d \theta}{k_{t+1}} .
$$

The fact that $\int_{S} Z_{t}^{s} d s=k_{t+1}$ follows from the market clearing condition for claims in (4). It turns out that there is a simple formula that characterizes the evolution of the wealth distribution in our economy. We specifically have the following proposition:

Proposition 2 For all $t, v \geq 0$, we have

$$
z_{t}^{s}=\xi_{t, v} z_{v}^{s}+\left(1-\xi_{t, v}\right) e^{s}
$$

where $\xi_{t, v}$ is defined by

$$
\xi_{t, v} \equiv \frac{k_{v+1} E_{t}\left[\sum_{\tau=t+1}^{\infty} \delta^{\tau-t} \frac{u_{1}\left(c_{\tau}, h_{\tau}\right)}{u_{1}\left(c_{t}, h_{t}\right)} c_{\tau}\right]}{k_{t+1} E_{v}\left[\sum_{\tau=v+1}^{\infty} \delta^{\tau-v} \frac{u_{1}\left(c_{\tau}, h_{\tau}\right)}{u_{1}\left(c_{v}, h_{v}\right)} c_{\tau}\right]} .
$$

\footnotetext{
${ }^{5}$ See Dimelis and Livada (1999) for a description of business cycle properties of income inequality indices in the United Kingdom, Italy and Greece.
} 
Proof. See Appendix A.

According to (10), the wealth distribution in a period $t$ can be represented as a linear combination of the wealth distribution in any other period $v$ and the skill distribution. The movements of the variable $\xi_{t, v}$ capture the entire effect of the aggregate dynamics on the wealth distribution.

A straightforward implication of our analysis is that any wealth distribution can be supported in the steady state. Indeed, if the representative consumer economy (6) starts in the steady state, then we have that $\xi_{t, v} \equiv 1$ for all $t, v$ and, therefore, the initial wealth distribution will be perpetuated, i.e., $z_{t}^{s}=z_{0}^{s}$ for all $t$ and $s$. Another case in which the model has trivial implications with regard to the evolution of the wealth distribution is when the initial wealth distribution coincides with the skill distribution. In such a case, the wealth distribution will always be the same, independently of the movements of the variable $\xi_{t, v}$.

Let us analyze the dynamics of the wealth distribution in a general case. Fix $v=0$ and denote $\xi_{t} \equiv \xi_{t, 0}$. Condition (10) implies

$$
\operatorname{corr}\left(z_{t}^{s}, y_{t}\right)=\operatorname{sign}\left|z_{0}^{s}-e^{s}\right| \operatorname{corr}\left(\xi_{t}, y_{t}\right)
$$

where sign $|x|$ is the sign of a variable $x$, and $\operatorname{corr}(x, y)$ is the correlation coefficient between variables $x$ and $y$.

In our model, the variable $\xi_{t}$ moves counter-cyclically. For example, we have $\operatorname{corr}\left(\xi_{t}, y_{t}\right) \simeq-0.6$ under the benchmark parametrization: $\eta=1$ (i.e., the period utility function is logarithmic), $\alpha=0.36, \delta=0.99, d=0.02, \mu=$ $1 / 3, \theta_{t}=\theta_{t-1}^{\rho} \exp \left(\varepsilon_{t}\right)$, where $\rho=0.95$ and $\varepsilon_{t} \sim N\left(0, \sigma^{2}\right)$ with $\sigma=0.007$. Our finding that $\operatorname{corr}\left(\xi_{t}, y_{t}\right)$ is negative proved to be robust to modifications in the model's parameters.

The counter-cyclical behavior of the variable $\xi_{t}$ can be understood by looking at the impulse response experiment shown in Figure 1. Here, the economy, which is initially in the steady state, experiences a positive permanent technology shock in period $t$. When the utility function is logarithmic, expression (11) takes a simple form:

$$
\xi_{t}=\frac{c_{t} / c_{0}}{k_{t+1} / k_{1}}
$$

On impact, both the consumption, $c_{t}$, and the capital, $k_{t+1}$, of the representative agent increase. However, given that the agent is risk-averse, the 
Figure 1. Impulse response functions under the benchmark parameterization. ${ }^{a}$
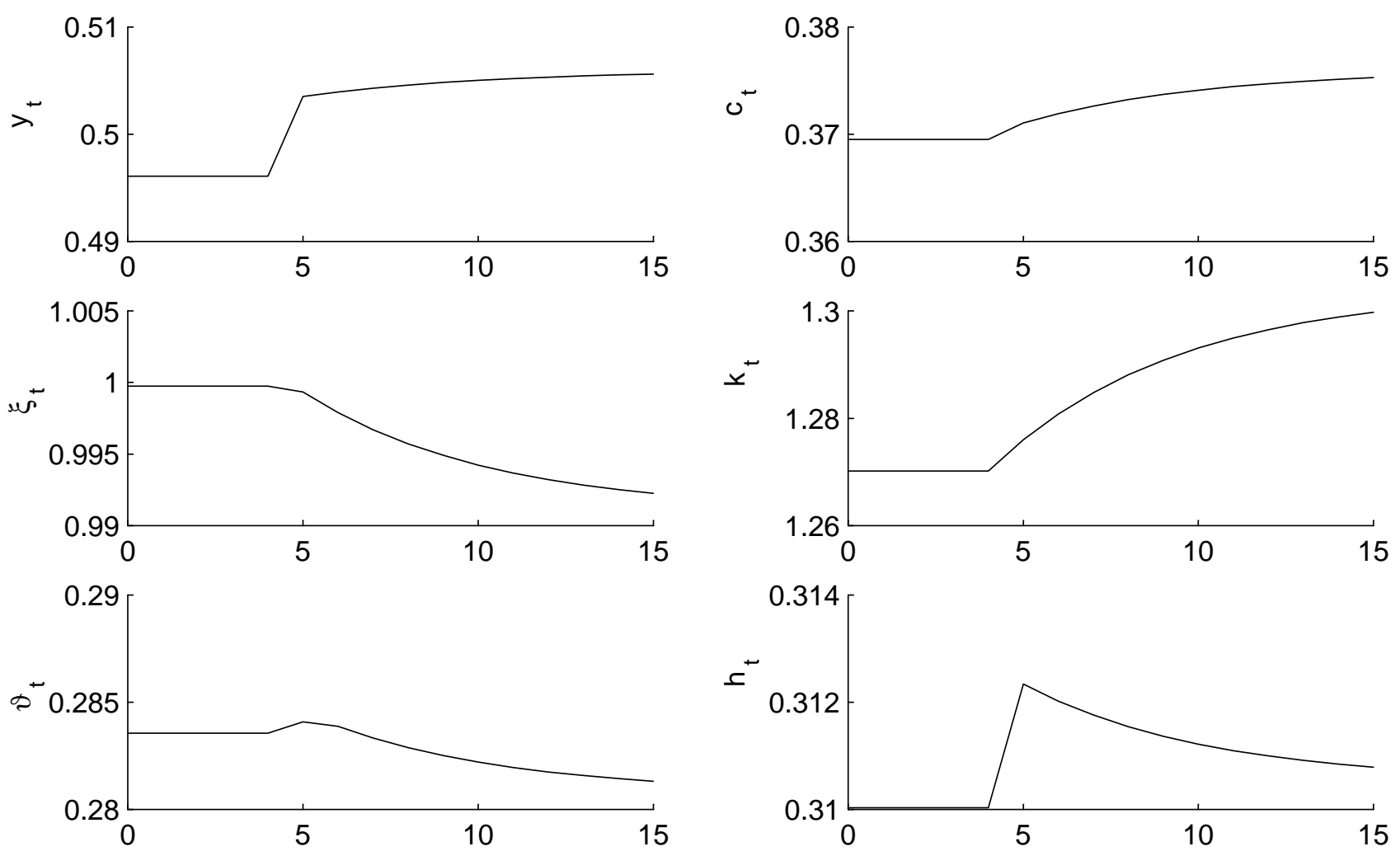

aParameter values: $\eta=1, \mu=1 / 3, \alpha=0.36, \delta=0.99, d=0.02, \rho=0.95, \sigma=0.007$. 
relative rise in consumption is lower than the increase in capital, so that $\xi_{t}$ goes down.

The fact that the variable $\xi_{t}$ moves counter-cyclically implies that in our model, the agent's $s$ wealth share, $z_{t}^{s}$, increases (decreases) during expansions, if her initial wealth endowment is lower than her skills, $z_{0}^{s}<e^{s}$ (higher than her skills, $\left.z_{0}^{s}>e^{s}\right)$. Unfortunately, we cannot test this prediction of the model because, as we have said, there is no sufficient empirical evidence on the dynamics of the wealth distribution over the business cycle.

We now focus on the dynamics of income distribution. We define the individual's income, $Y_{t}^{s}$, as the sum of the returns on her asset portfolio and her labor earnings expressed in terms of current consumption good,

$$
Y_{t}^{s} \equiv r_{t} k_{t}^{s}+m_{t}^{s}\left(\theta_{t}\right)+n_{t}^{s} e^{s} w_{t}
$$

It follows from definition (14) that the individual income depends on the composition of the agent's asset portfolio, i.e., on how much capital and how many units of claims of each type $\theta \in \Theta$ were purchased by the agent in the previous period. Note that in our economy the equilibrium composition of individual asset portfolio is not uniquely determined. ${ }^{6}$ As a result, there is indeterminacy in the individual income.

This indeterminacy is due to the assumption of complete markets. In our economy, the agents are not concerned about how much income they receive in each period, but rather about how much income they receive over their life-time. Consequently, the agents are indifferent between any sequences of asset portfolios as long as they lead to the same expected life-time payoff. To overcome the problem of indeterminacy, we need to impose some additional restrictions on the composition of the agents' portfolios. The restriction we use is that the state contingent claims are not traded so that only the capital stock is in operation. Since holding the portfolio, which is composed of the capital stock only, is optimal, such a restriction is consistent with our definition of equilibrium.

Let $y_{t}^{s}$ be the share of agent's $s$ income within the total income,

$$
y_{t}^{s} \equiv \frac{Y_{t}^{s}}{\int_{S} Y_{t}^{s} d s} .
$$

Concerning the income distribution, we get the following result.

\footnotetext{
${ }^{6}$ The reason for the indeterminacy is that there are more assets traded in the equilibrium $(\Theta$ types of claims and the capital stock) than the economy's states $(\Theta)$. As a consequence, one of the assets will be always a linear combination of the others.
} 
Proposition 3 For all $t \geq 1$ and $v \geq 0$, we have

$$
y_{t}^{s}=\vartheta_{t, v} z_{v}^{s}+\left(1-\vartheta_{t, v}\right) e^{s},
$$

where $\vartheta_{t, v}$ is defined by

$$
\vartheta_{t, v} \equiv \alpha \xi_{t-1, v}+\frac{\left(1-1 / h_{t}\right)(1-\alpha) \mu k_{v+1}}{E_{v}\left[\sum_{\tau=v+1}^{\infty} \delta^{\tau-v} \frac{u_{1}\left(c_{\tau}, h_{\tau}\right)}{u_{1}\left(c_{v}, h_{v}\right)} c_{\tau}\right]}
$$

Proof. See Appendix A.

Thus, similar to wealth distribution, the income distribution in our economy is given by a linear combination of the wealth distribution in some period $v$ and the skill distribution. Again, only one aggregate variable, $\vartheta_{t, v}$, is needed to fully characterize the evolution of the income distribution.

Let us fix $v=0$ and denote $\vartheta_{t} \equiv \vartheta_{t, v}$. Condition (16) yields the formula for the income distribution dynamics, which parallels the one previously obtained for the wealth distribution dynamics,

$$
\operatorname{corr}\left(y_{t}^{s}, y_{t}\right)=\operatorname{sign}\left|z_{0}^{s}-e^{s}\right| \operatorname{corr}\left(\vartheta_{t}, y_{t}\right) \text {. }
$$

We find, by simulation, that the variable $\vartheta_{t}$ moves counter-cyclically. However, $\operatorname{corr}\left(\vartheta_{t}, y_{t}\right)$ is weaker than $\operatorname{corr}\left(\xi_{t}, y_{t}\right)$. For example, under our benchmark parameterization, we have $\operatorname{corr}\left(\vartheta_{t}, y_{t}\right) \simeq-0.2$, and similar values of this statistic are obtained in a wide range of the model's parameters.

The determinants of the correlation $\operatorname{corr}\left(\vartheta_{t}, y_{t}\right)$ can be seen from the impulse response experiment in Figure 1. In response to the shock, the aggregate labor input, $h_{t}$, increases, which pushes $\vartheta_{t}$ up. The variable $\xi_{t}$ however goes down, and its reduction is subsequently transmitted to $\vartheta_{t+1}$. Starting from period $t+1$, the effect associated with $\xi_{t}$ drives $\vartheta_{t+1}$ down. Given that $\operatorname{corr}\left(\vartheta_{t}, y_{t}\right)$ is, overall, negative, we conclude that the agent's $s$ income share, $y_{t}^{s}$, is pro-cyclical (counter-cyclical) when $z_{0}^{s}<e^{s}\left(z_{0}^{s}>e^{s}\right)$.

A counter-cyclical behavior of $\xi_{t}$ and $\vartheta_{t}$ implies that wealth and income inequality in our economy is counter-cyclical. Indeed, the weights of the initial wealth distribution, given by $\xi_{t}$ and $\vartheta_{t}$ in (10) and (16), respectively, decrease during expansions and increase during recessions. The opposite is true for the weights of the skill distribution, $\left(1-\xi_{t}\right)$ and $\left(1-\vartheta_{t}\right)$. The (initial) wealth distribution in the data, however, is more unequal than the 
skill distribution. ${ }^{7}$ As a result, expansions (recessions) have an equalizing (disequalizing) effect on the income and wealth distributions.

As far as the dynamics of the income distribution are concerned, the steady state value of $\vartheta_{t}$ is around 0.3 , which implies that, near the steady state, $\vartheta_{t}$ lies in the interval $[0,1]$. We can therefore state that, during expansions, income distribution moves towards skill distribution, $\left\{e^{s}\right\}^{s \in S}$, while during recessions, it does toward the initial wealth distribution, $\left\{z_{0}^{s}\right\}^{s \in S}$. This statement does not apply, however, to the wealth distribution, because the variable $\xi_{t}$ does not, in general, belong to the interval $[0,1]$ : it is equal to 1 in period $t=0$, and it is typically smaller (larger) than 1 when the economy expands (contracts).

We shall now analyze the mechanism behind the counter-cyclical behavior of inequality in the model. Formulas (10) and (16) are not suitable for this purpose because they characterize the evolution of the income and wealth distributions in terms of aggregate dynamics, and do not reveal what is happening at the individual level. We therefore focus on the decisions of heterogeneous agents. Let us re-write the agent's $s$ income and wealth shares as follows:

$$
\begin{gathered}
y_{t}^{s}=\alpha z_{t-1}^{s}+(1-\alpha) n_{t}^{s} e^{s} / h_{t} \\
z_{t}^{s}=z_{t-1}^{s}\left[\frac{1-d+\frac{r_{t} k_{t}^{s}+n_{t}^{s} e^{s} w_{t}-c_{t}^{s}}{z_{t-1}^{s} k_{t}}}{1-d+\frac{r_{t} k_{t}+h_{t} w_{t}-c_{t}}{k_{t}}}\right]=z_{t-1}^{s}\left[\frac{1+\frac{e^{s}}{z_{t-1}^{s}}\left(n_{t}^{s}-\mu\right) \phi_{t}}{1+\left(h_{t}-\mu\right) \phi_{t}}\right],
\end{gathered}
$$

where $\phi_{t} \equiv \frac{w_{t}}{\left(1-d+r_{t}\right) k_{t}(1-\mu)}$. Equation (19) follows by the linear homogeneity of the Cobb-Douglas production function; equation (20) is obtained by using budget constraint (2) and the intratemporal first-order condition relating consumption and working hours (see formula (29) in Appendix A).

As seen from (19) and (20), the business cycle behavior of $y_{t}^{s}$ and $z_{t}^{s}$ is determined by the responsiveness to shocks of $n_{t}^{s}$ relative to $h_{t}$ and of $\frac{e^{s}}{z_{t-1}^{s}} n_{t}^{s}$ relative to $h_{t}$, respectively. The following proposition characterizes the individual labor choices by comparing them with the corresponding decisions of the representative consumer.

\footnotetext{
${ }^{7}$ For example, Quadrini and Ríos-Rull (1997) report that in the 1992 Survey of Consumption Financing data set, the wealth shares of the bottom $40 \%$ and the top $1 \%$ of the population are $2.2 \%$ and $28.2 \%$, respectively, while the corresponding earnings (skill) shares are $10.3 \%$ and $14.1 \%$, respectively.
} 
Proposition 4 For an agent with $z_{t-1}^{s} \lesseqgtr e^{s}$, we have

$$
\begin{aligned}
& \frac{\partial n_{t}^{s}}{\partial \theta_{t}} \lesseqgtr \frac{\partial h_{t}}{\partial \theta_{t}}, \\
& \frac{e^{s}}{z_{t-1}^{s}} \frac{\partial n_{t}^{s}}{\partial \theta_{t}} \gtreqless \frac{\partial h_{t}}{\partial \theta_{t}} .
\end{aligned}
$$

Proof. See Appendix A.

Suppose that the economy is in the steady state in period $t-1$ and that it experiences a positive technology shock in period $t$. All agents increase their working hours. However, in accordance with (21), agents whose skills are high relative to wealth, $z_{t-1}^{s}>e^{s}$, increase their working hours more than do agents whose skills are low relative to wealth, $z_{t-1}^{s}<e^{s}$. It follows from (19) that the income shares of agents with $z_{t-1}^{s}>e^{s}\left(z_{t-1}^{s}<e^{s}\right)$ go up (down) which corresponds to the shift of the income distribution $\left\{y_{t}^{s}\right\}^{s \in S}$ towards the wealth distribution $\left\{z_{t-1}^{s}\right\}^{s \in S}$. As a result, in period $t$, income inequality rises. (In our impulse response experiment, this effect is captured by an increase in $\vartheta_{t}$ immediately after the shock).

Wealth inequality, however, falls in period $t$. Condition (20) implies that the change in the agent's $s$ wealth share is determined by how much she invests relative to her wealth, $\frac{r_{t} k_{t}^{s}+n_{t}^{s} s^{s} w_{t}-c_{t}^{s}}{z_{t-1}^{s} k_{t}}$. By result (22), we have that $\frac{\partial}{\partial \theta_{t}}\left[\frac{e^{s}}{z_{t-1}^{s}}\left(n_{t}^{s}-\mu\right)-\left(h_{t}-\mu\right)\right]$ is negative (positive) for agents with $z_{t-1}^{s}>e^{s}$ $\left(z_{t-1}^{s}<e^{s}\right)$. Thus, an increase in investment (income) relative to wealth is lower for agents with $z_{t-1}^{s}>e^{s}$ than for those with $z_{t-1}^{s}<e^{s}$ (even though the opposite is true for their income levels). The intuition behind this result is as follows: "Rich and low-productive" agents cannot significantly increase their wealth by working more hours, because labor income represents only a small fraction of their wealth. On the contrary, "poor and highly-productive" agents can achieve a substantial percentage increase in their wealth by working just a few more hours.

The $t$-period wealth distribution affects the $t+1$-period income distribution because wealth accumulated in $t$ determines capital income in $t+1$. It follows from (19) that the income shares of agents with $z_{t-1}^{s}>e^{s}\left(z_{t-1}^{s}<e^{s}\right)$ decrease (increase) in period $t+1$, i.e., the income distribution $\left\{y_{t+1}^{s}\right\}^{s \in S}$ moves in the direction of the skill distribution $\left\{e^{s}\right\}^{s \in S}$. The result is that income inequality begins to fall. (In our impulse response experiment, this 
effect corresponds to a decrease in $\vartheta_{t}$ from period $t+1$ onwards). The countercyclical movement of income inequality in our model is therefore due to the wealth-distribution effect.

The model's prediction that income inequality is counter-cyclical agrees with the previously discussed findings of Dimelis and Livada (1999), that the Gini and Theil coefficients of the U.S. income distribution are weakly counter-cyclical. The empirical evidence documented by Castañeda et al. (1998), indicates, however, that expansions have an ambiguous effect on income inequality. Specifically, inequality between the bottom and middle deciles goes down, while inequality between the middle and top deciles goes up. If the top-income group is excluded from the sample, the behavior of income inequality would be counter-cyclical, as predicted by our model. ${ }^{8}$

The empirical regularities discussed provide indirect evidence in support of relation (16) which, according to our model, describes the evolution of income distribution over the business cycle. In the following section, we perform a direct test of this relation based upon micro-data on the contributions to income inequality of wage income versus wealth income.

\section{Empirical analysis}

In this section, we conduct an empirical test of the model. We first study whether the data support our hypothesis that income distribution moves between skill and wealth distributions over the business cycle. We then derive and estimate the equation that describes the behavior of the coefficient of variation of income distribution in the model. For our empirical study, we use data on the U.S. economy. The household data is taken from the Panel Study of Income Dynamics (PSID). The aggregate time-series come from the data base of the U.S. Department of Labor and the U.S. Department of Commerce. The sample period is 1967-1991. The further description of the data is provided in Appendix B.

\subsection{Distance between the distributions}

According to our model, income distribution moves towards skill distribution during expansions, and towards the initial wealth distribution during

\footnotetext{
${ }^{8}$ The top-income group consists of executives who get high bonuses during expansions. Our model is obviously too simple to account for such evidence.
} 
recessions. To examine whether this implication agrees with the data, we study the business cycle behavior of the distances between income and skill distributions and between income and wealth distributions.

As a measure of the distance between two functions $G_{1}: U \subseteq \mathbb{R} \rightarrow \mathbb{R}$ and $G_{2}: U \subseteq \mathbb{R} \rightarrow \mathbb{R}$, we use the Kolmogorov distance (see, e.g., Shorack and Wellner, 1986, Section 2.1)

$$
D\left(G_{1}, G_{2}\right) \equiv \sup _{u \in U}\left|G_{1}(u)-G_{2}(u)\right| .
$$

To characterize the empirical distributions of income, wealth and skills, we use two alternative representations, the Lorenz curve and the cumulative distribution function. Let $\left\{x^{s}\right\}^{s \in S}$ be a discrete and finite set. The Lorenz curve at points $j / S, j=0, \ldots, S$, is defined by $L_{\left\{x^{s}\right\}}(0)=0$ and $L_{\left\{x^{s}\right\}}(j / S)=$ $\sum_{s=1}^{j} x^{(s)} / \sum_{s=1}^{S} x^{s}$, where $\left\{x^{(s)}\right\}^{s \in S}$ is the ascending sequence composed of the elements of $\left\{x^{s}\right\}^{s \in S}$. The Lorenz curve in other points of the interval $[0,1]$ is obtained by linear interpolation. The cumulative distribution function $F_{\left\{x^{s}\right\}}: \mathbb{R} \rightarrow[0,1]$ is defined by $F_{\left\{x^{s}\right\}}(u) \equiv \frac{1}{S} \sum_{s=1}^{S} I\left(x^{s} \leq u\right)$, where $I(A)$ is the indicator function, which is equal to 1 , if event $A$ occurs, and to 0 , otherwise.

We interpret an agent in the model as a household in the data. Thus, the agent's income and wealth are those of the household. The agent's skills are proxied by the wage of the household's head.

The data on wealth are available from the PSID for the years 1984 and 1989. We report only the results for the distances between income distribution and the 1989 wealth distribution, $\left\{z_{1989}^{s}\right\}^{s \in S}$. The results obtained with the 1984 wealth distribution are similar.

The skill distribution is assumed to be time-invariant in the model. However, it changes in the data over time. To compute the distance between the income and skill distributions, we therefore explore two alternatives: one, when the skill distribution changes over time (in each period $t$, it is proxied by $t$-period wage distribution), and another, when the skill distribution is the same for all periods (it is represented by the distribution composed of the data on wages over the entire sample period). We find that, in both cases, the distance between income and skill distributions displays similar business cycle properties. We report only the results obtained with the time-varying skill distribution, $\left\{e_{t}^{s}\right\}^{s \in S}$.

We also investigate whether the model's distributional implications hold for different income groups. Specifically, in each period $t$, we split the sam- 
ple into five equal-sized income groups, i.e., the poorest $20 \%$, the next $20 \%$, etc. We denote these groups by $[0,0.2],[0.2,0.4],[0.4,0.6],[0.6,0.8],[0.8,1.0]$ and refer to them as quintiles. Furthermore, to examine the evolution of the income shares of the top-income earners, we consider, separately, three upper-income groups, i.e., [0.9, 0.95], [0.95, 0.99], [0.99, 1.0]. For each income group $\left[b_{1}, b_{2}\right]$, we construct the Lorenz curves of the income and skill distributions, denoted by $L_{\left\{y_{t}^{s}\right\}}^{\left[b_{1}, b_{2}\right]}$ and $L_{\left\{e_{t}^{s}\right\}}^{\left[b_{1}, b_{2}\right]}$, respectively, and compute the distance between them, $D\left(L_{\left\{y_{t}^{s}\right\}}^{\left[b_{1}, b_{2}\right]}, L_{\left\{e_{t}^{s}\right\}}^{\left[b_{1}, b_{2}\right]}\right) .9$ The results obtained with the cumulative distribution functions are similar to those obtained with the Lorenz curves and are therefore not reported.

To study the behavior of the distances over the business cycle, we first log and then detrend the time-series for distances and output, by using the Hodrick-Prescott filter with a smoothing parameter of 100 . This value of the smoothing parameter is chosen following Castañeda et al. (1998).

Figure 2 and Figure 3 plot the computed time-series for the distances between the income and wealth distributions and between the income and skill distributions, respectively. In the left- and right-hand columns, we provide the undetrended series and the corresponding cyclical components, respectively. To appreciate the business cycle behavior of the distance series, in the right-hand columns we also provide the detrended output series. Firstly, we notice that the distances computed with the Lorenz curves and those computed with the cumulative distribution functions follow similar patterns, both in the long run and over the business cycle.

Regarding the long-run behavior, we observe that income distribution moves from a relatively equal skill distribution to a relatively unequal wealth distribution, which implies that income inequality rises over the sample period. As pointed-out before, long-run tendencies like this cannot be explained in the context of our stationary model.

As far as the business cycle dynamics are concerned, we detect a pronounced counter-cyclical pattern of the distance between income and skill distributions. In the case of the distance between income and wealth distributions, the evidence is not so strong, although a certain pro-cyclical pattern can be perceived. To make a better judgement, we compute the sample cor-

\footnotetext{
${ }^{9}$ We cannot proceed by computing the time series for distances between the income and wealth distributions of different income groups the same way. Given that our income groups are composed of distinct households in different periods, we can only compute such distances for the years 1984 and 1989, for which data on wealth are available.
} 
Figure 2. The distance between the income and skill distributions in the U.S economy.
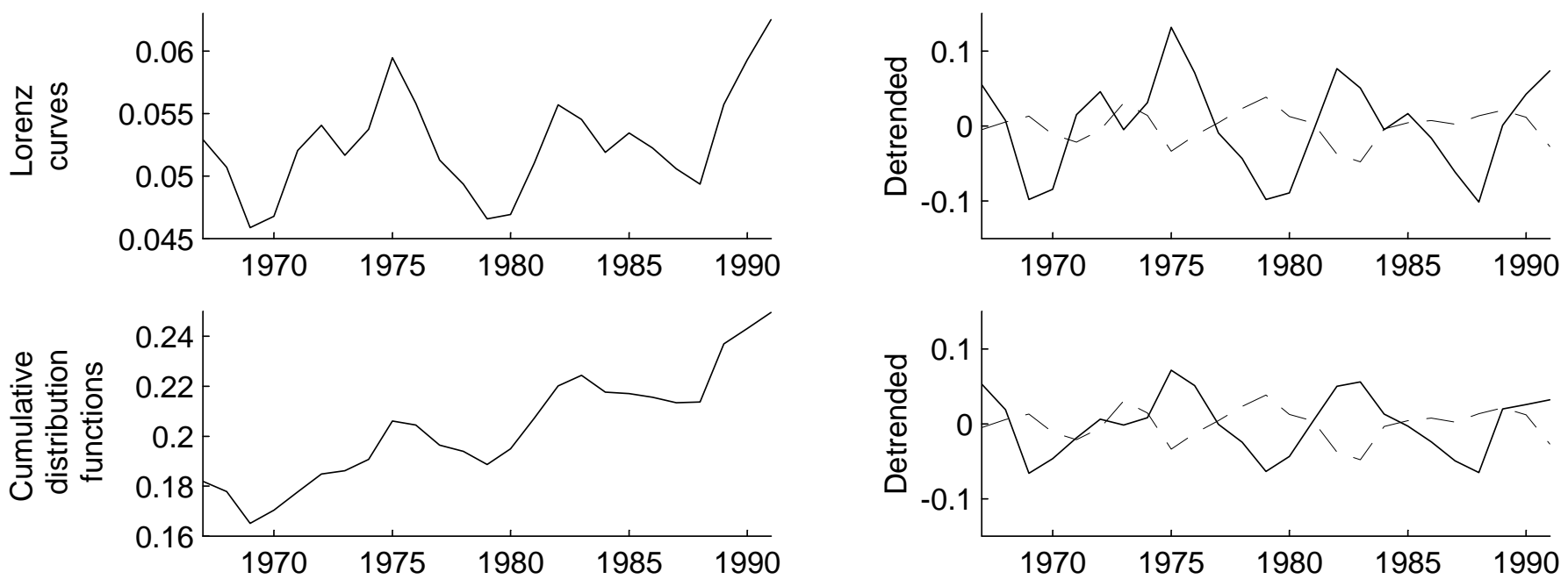

- Distance
- Output


Figure 3. The distance between the income and wealth distributions in the U.S economy.
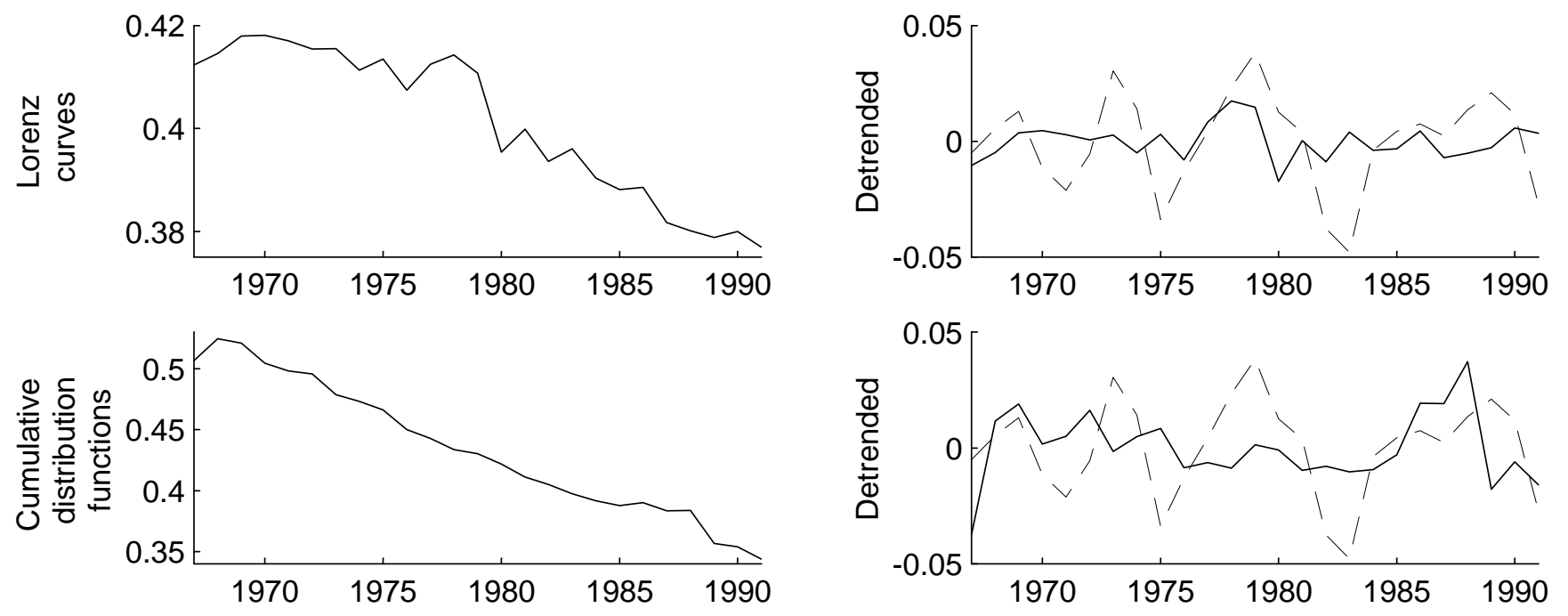

_ Distance
_ - Output


relations between the detrended distance and output series. The results are reported in Table 1. As can be seen, the correlation of output with the distance between the income and skill distributions is about -0.6 , while the correlation of output with the distance between the income and wealth distributions is about 0.2. Taken as a whole, these findings are favorable to our theoretical model.

In Figure 4 and Figure 5, we plot the distance series corresponding to the income quintiles and the three upper-income groups, respectively. In Table 1, we report the correlations of the distances with output. In general, the results for the income groups are similar to those for the entire sample: the distances show an upward long-run trend and move counter-cyclically. The only exception is the $[0.9,0.95]$ income group for which the distance between the income and skill distributions is weakly pro-cyclical. ${ }^{10}$

Finally, we verify the robustness of our findings with respect to the concept of the distance used. We specifically repeat all the previous computations, using an alternative measure of the distance, which is the Wasserstein distance, defined as $\left[\int_{U}\left\{G_{1}(u)-G_{2}(u)\right\}^{2} d u\right]^{1 / 2}$ (see, e.g., Shorack and Wellner, 1986, Section 2.6). The results we obtain with the Wasserstein distance prove to be very close to those we got with the Kolmogorov distance.

\subsection{Coefficient of variation of the income distribution}

Our analysis implies that the evolution of an aggregate measure of income inequality, such as the Coefficient of Variation $(C V)$ of the income distribution, can be fully characterized by the dynamics of the representative consumer economy (6). Indeed, substituting (16) in the definition of the $C V$ of the income distribution, we arrive at

$$
C V_{t}^{2} \equiv \int_{S}\left(y_{t}^{s}-1\right)^{2} d s=a_{1}+a_{2} \vartheta_{t}+a_{3} \vartheta_{t}^{2}
$$

with the coefficients $a_{1}, a_{2}$ and $a_{3}$ being given by

$$
a_{1}=\int_{S}\left(e^{s}-1\right)^{2} d s, \quad a_{2}=2 \int_{S}\left(z_{0}^{s} e^{s}-\left(e^{s}\right)^{2}\right) d s, \quad a_{3}=\int_{S}\left(z_{0}^{s}-e^{s}\right)^{2} d s .
$$

\footnotetext{
${ }^{10}$ The pro-cyclical behavior of the distance here is presumably related to the previously mentioned fact that executives get high bonuses during expansions.
} 
Table 1. Selected second moment properties of the distances between the income and skill distributions and between the income and wealth distributions in the U.S. economy.

\begin{tabular}{|c|c|c|}
\hline$x_{t}$ & $\overline{\sigma_{x} / \sigma_{y}}$ & $\overline{c o r r}\left(x_{t}, y_{t}\right)$ \\
\hline \multicolumn{3}{|l|}{ Total sample } \\
\hline$D\left(L_{\left\{y_{t}^{s}\right\}}, L_{\left\{e_{t}^{s}\right\}}\right)$ & 2.9714 & -0.6387 \\
\hline$D\left(F_{\left\{y_{t}^{s}\right\}}, F_{\left\{e_{t}^{s}\right\}}\right)$ & 1.9159 & -0.6121 \\
\hline$D\left(L_{\left\{y_{t}^{s}\right\}}, L_{\left\{z_{1989}^{s}\right\}}\right)$ & 0.3657 & 0.1916 \\
\hline$D\left(F_{\left\{y_{t}^{s}\right\}}, F_{\left\{z_{1989}^{s}\right\}}\right)$ & 0.7183 & 0.1806 \\
\hline \multicolumn{3}{|l|}{ Income quintiles } \\
\hline$D\left(L_{\left\{y_{t}^{s}\right\}}^{[0,0.2]}, L_{\left\{e_{t}^{s}\right\}}^{[0,0.2]}\right)$ & 2.2757 & -0.2900 \\
\hline$D\left(L_{\left\{y_{t}^{s}\right\}}^{[0.2,0.4]}, L_{\left\{e_{t}^{s}\right\}}^{[0.2,0.4]}\right)$ & 2.5517 & -0.6080 \\
\hline$D\left(L_{\left\{y_{t}^{s}\right\}}^{[0.4,0.6]}, L_{\left\{e_{t}^{s}\right\}}^{[0.4,0.6]}\right)$ & 2.1854 & -0.4963 \\
\hline$D\left(L_{\left\{y_{t}^{s}\right\}}^{[0.6,0.8]}, L_{\left\{e_{t}^{s}\right\}}^{[0.6,0.8]}\right)$ & 1.6651 & -0.3951 \\
\hline$D\left(L_{\left\{y_{t}^{s}\right\}}^{[0.8,1]}, L_{\left\{e_{t}^{s}\right\}}^{[0.8,1]}\right)$ & 2.3840 & -0.2888 \\
\hline \multicolumn{3}{|l|}{ Top income groups } \\
\hline$D\left(L_{\left\{y_{t}^{s}\right\}}^{[0.0 .95]}, L_{\left\{e_{t}^{s}\right\}}^{[0.09 .95]}\right)$ & 2.2877 & 0.1401 \\
\hline$D\left(L_{\left\{y_{t}^{s}\right\}}^{[0.95,0.99]}, L_{\left\{e_{t}^{s}\right\}}^{[0.95,0.99]}\right)$ & 3.8590 & -0.4786 \\
\hline$D\left(L_{\left\{y_{t}^{s}\right\}}^{[0.99,1]}, L_{\left\{e_{t}^{s}\right\}}^{[0.99,1]}\right)$ & 10.5284 & -0.1039 \\
\hline
\end{tabular}

Note: $\sigma_{x}$ is the standard deviation of a variable $x_{t} ; \operatorname{corr}\left(x_{t}, y_{t}\right)$ is the correlation coefficient between variables $x_{t}$ and $y_{t}$. All the statistics reported are computed after the logging and detrending the corresponding variables by using the Hodrick-Prescott filter with a smoothing parameter of 100 . The standard deviation of output, $\sigma_{y}$, is equal to $2.12 \%$. 
Figure 4. The distance between the Lorenz curves of the income and skill distributions in the U.S economy: income quintiles.
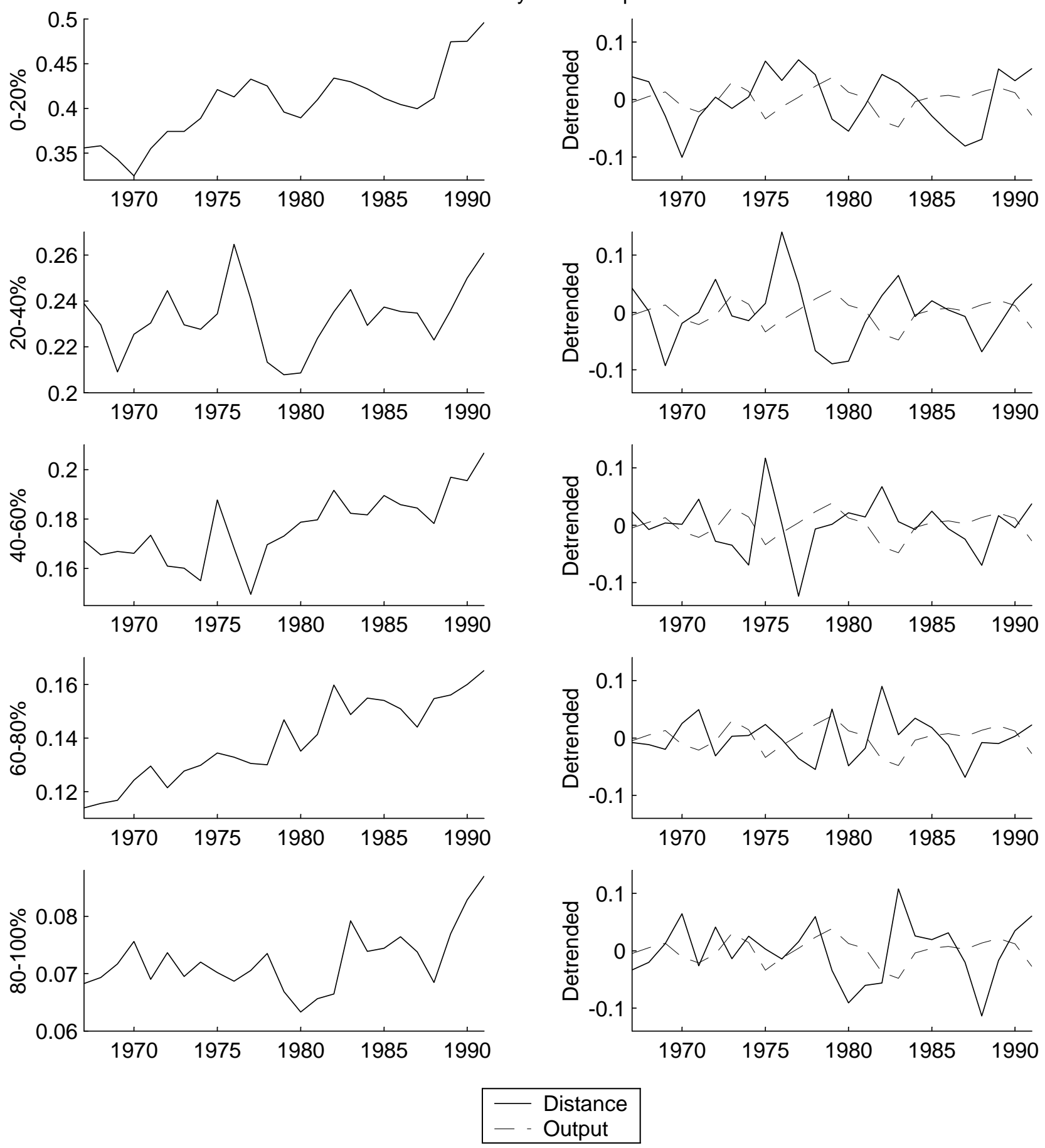
Figure 5. The distance between the Lorenz curves of the income and skill distributions in the U.S economy: top income groups.
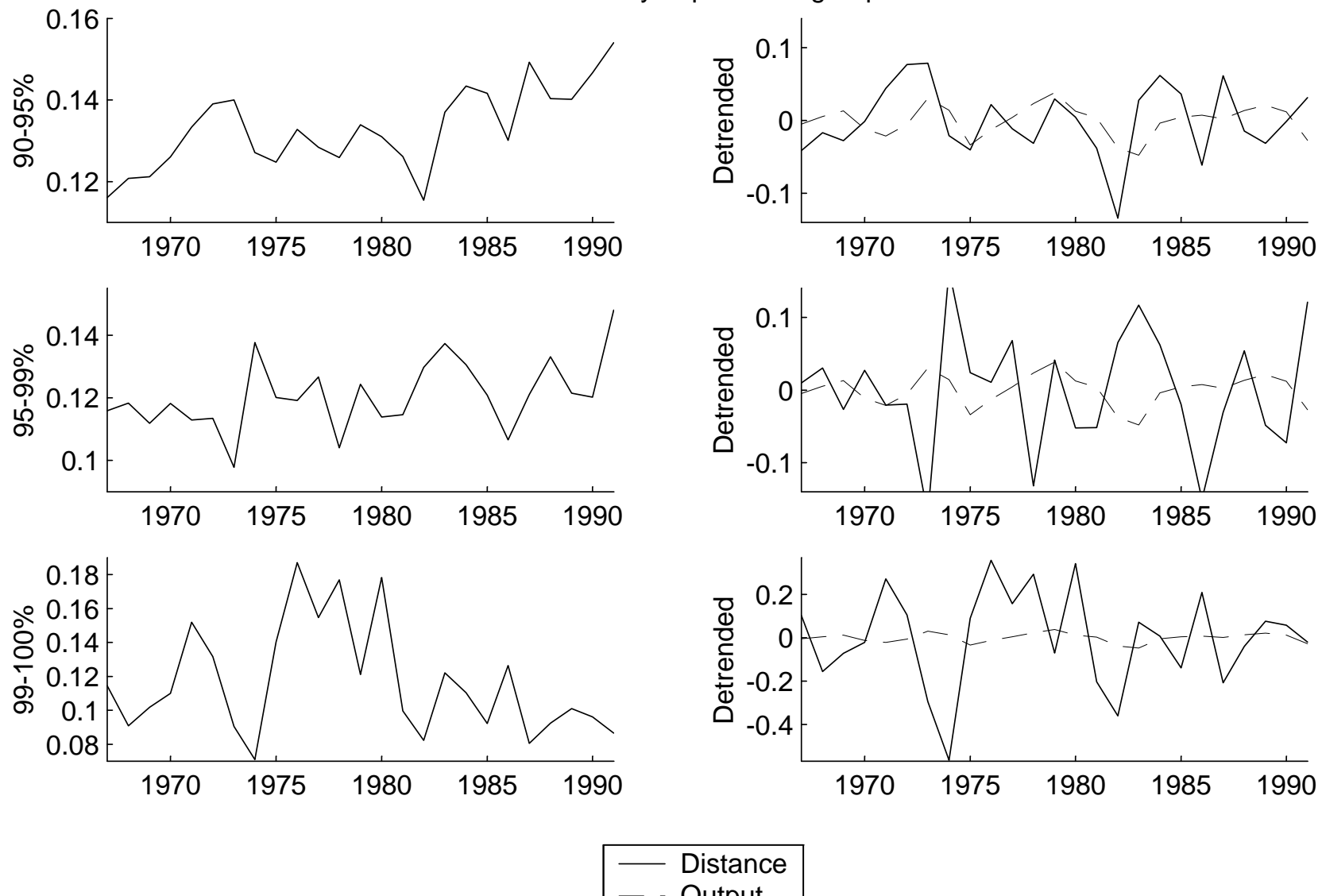
Here, for a clearer exposition, we fix $v=0$. Formula (24) provides a basis for econometric estimation. We focus on the case of the logarithmic utility function. Substituting (13), (17) into (24) yields

$$
\begin{aligned}
C V_{t}^{2}=\beta_{1}+\beta_{2} \frac{c_{t-1}}{k_{t}}+ & \beta_{3}\left(\frac{c_{t-1}}{k_{t}}\right)^{2}+\beta_{4}\left(1-\frac{1}{h_{t}}\right)+ \\
& +\beta_{5}\left(1-\frac{1}{h_{t}}\right)^{2}+\beta_{6}\left(1-\frac{1}{h_{t}}\right)\left(\frac{c_{t-1}}{k_{t}}\right)+\varepsilon_{t},
\end{aligned}
$$

where $\varepsilon_{t}$ is an error term, and the coefficients $\beta_{1}, \ldots, \beta_{6}$ are defined by

$$
\begin{gathered}
\beta_{1}=a_{1}, \beta_{2}=\frac{a_{2} \alpha k_{1}}{c_{0}}, \beta_{3}=a_{3}\left(\frac{\alpha k_{1}}{c_{0}}\right)^{2}, \beta_{4}=\frac{a_{2}(1-\alpha)(1-\delta) \mu k_{1}}{\delta c_{0}}, \\
\beta_{5}=\frac{\beta_{3} \beta_{4}^{2}}{\beta_{2}^{2}}, \quad \beta_{6}=\frac{2 \beta_{3} \beta_{4}}{\beta_{2}} .
\end{gathered}
$$

According to (25), the coefficients $a_{1}$ and $a_{3}$ are always positive, and the sign of the coefficient $a_{2}$ is determined by specific wealth and skill distributions. On the basis of $(27),(28)$, we would therefore expect the coefficients $\beta_{1}, \beta_{3}$, $\beta_{5}, \beta_{6}$ to be positive and the sign of the coefficients $\beta_{2}, \beta_{4}$ to coincide with that of $a_{2}$.

We estimate the regression equation (26) subject to the restrictions in (28). The estimation is carried out by constrained maximum likelihood under the assumption of normal errors. The results of the estimation are presented in the first panel of Table 2, with two different types of $t$-statistics, the Hessian-based and quasi-maximum-likelihood, which are robust to misspecification (see, e.g., White, 1982). The adjusted coefficient of determination shows that our model can explain about $60 \%$ of the total variation in the squared coefficient of variation of income distribution. Furthermore, as predicted by the model, $\beta_{1}$ and $\beta_{3}$ have a positive sign, and $\beta_{2}$ and $\beta_{4}$ have an identical (negative) sign.

To examine the validity of the restrictions in (28), we estimate the unrestricted version of equation (26). This estimation is performed by Ordinary Least-Squares (OLS), which is equivalent to maximum likelihood with normal errors. The results are presented in the second panel of Table 2, as well as two types of $t$-statistics, OLS and heteroskedasticity-consistent (see, e.g., White, 1980). As can been seen, the estimated beta coefficients in the unrestricted and restricted regressions differ substantially, which is probably due 
Table 2. The CV of the income distribution regressions: estimates for the U.S. economy.

\begin{tabular}{|c|c|c|c|c|c|c|c|c|c|}
\hline & $\beta_{1}$ & $\beta_{2}$ & $\beta_{3}$ & $\beta_{4}$ & $\beta_{5}$ & $\beta_{6}$ & $\sum \widehat{\varepsilon}_{t}^{2}$ & $\bar{R}^{2}$ & $D .-W$. \\
\hline \multicolumn{10}{|l|}{ Restricted } \\
\hline Coefficient & 8.040 & -38.17 & 48.52 & -0.975 & - & - & 0.6011 & 0.5961 & 1.9417 \\
\hline$t_{1}$ & 1.055 & -0.558 & 0.364 & -0.188 & & & & & \\
\hline$t_{2}$ & 0.869 & -0.372 & 0.232 & -0.113 & & & & & \\
\hline \multicolumn{10}{|l|}{ Unrestricted } \\
\hline Coefficient & 11.506 & 52.658 & 13.685 & 16.810 & 6.337 & 31.560 & 0.5600 & 0.6237 & 2.0435 \\
\hline$t_{1}$ & 1.087 & 0.570 & 0.157 & 1.033 & 1.154 & 1.058 & & & \\
\hline$t_{2}$ & 1.365 & 0.988 & 0.216 & 2.356 & 2.657 & 2.002 & & & \\
\hline
\end{tabular}

Note: $\quad \sum \widehat{\varepsilon}_{t}^{2}$ is the squared sum of residuals; $\bar{R}^{2}$ is the adjusted coefficient of determination; $D .-W$.is the Durbin-Watson statistics; in the restricted regression, $t_{1}$ and $t_{2}$ are, respectively, the Hession-based and quasi-maximum-likelihood $t$-statistics; in the unrestricted regression, $t_{1}$ and $t_{2}$ are, respectively, the OLS and heterogeneity-consistent $t$-statistics. 
to a problem of multi-collinearity. The global fit of the unrestricted regression, however, is close to that of the restricted one (the adjusted coefficient of determination in the former case is only $2.8 \%$ higher than in the latter one). We perform the formal test of the validity of the restrictions in (28) by computing the likelihood-ratio statistic. This statistic proved to be very low $(p-$ value $=0.5167)$, which means that the null hypothesis that the restrictions in (28) hold is accepted for any reasonable significance level. We arrive at the same conclusion when we use Wald and Lagrange-multiplier tests.

\section{Conclusion}

This paper studies the business cycle behavior of income and wealth distributions in a heterogeneous agents version of the standard neoclassical growth model. Heterogeneity is in two dimensions, initial endowment and non-acquired skills. We show that if markets are complete and agents have identical preferences of the CRRA type, the evolution of the income and wealth distributions in the model is fully characterized by the dynamics of the associated representative consumer setup. Two implications of this result for the income distribution dynamics are as follows: First, the income distribution approaches the skill distribution and the initial wealth distribution during expansions and recessions, respectively, which suggests that income inequality follows a counter-cyclical pattern. Second, the evolution of the coefficient of variation of the income distribution is completely determined by the dynamics of the macroeconomic variables. We find that these predictions of the model agree well with the U.S. data.

\section{References}

[1] Atkinson, A. B., Bourguignon, F., 2000, Handbook of income distribution, vol. 1, Amsterdam: North-Holland.

[2] Caselli, F., Ventura, J., 2000. A representative consumer theory of distribution, American Economic Review 90(4), 909-926.

[3] Castañeda, A., Diaz-Giménez, J., Ríos-Rull, J.V., 1998. Exploring the income distribution business cycle dynamics, Journal of Monetary Economics 42(1), 93-130. 
[4] Chatterjee, S., 1994. Transitional dynamics and the distribution of wealth in a neoclassical growth model, Journal of Public Economics $54,97-119$.

[5] Dimelis, S., Livada, A., 1999. Inequality and business cycles in U.S. and European Union countries, International Advances in Economic Research, 5(3), 321-338.

[6] Gastwirth, J.L., 1972. The estimation of the Lorenz curve and Gini index, Review of Economics and Statistics 54, 306-316.

[7] Gorman, W., 1953. Community preference field, Econometrica 21, 63-80.

[8] Juster, F., Stafford, F., 1991. The allocation of time: empirical findings, behavioral models, and problems of measurement, Journal of Economic Literature 29, 471-522.

[9] Kydland, F, 1984. Labor-force heterogeneity and the business cycle, Carnegie-Rochester Conference series on Public Policy 21, 173-208.

[10] Kydland, F., Prescott, E., 1982. Time to build and aggregate fluctuations, Econometrica 50, 1345-70.

[11] Maliar, L., Maliar, S., 2001. Heterogeneity in capital and skills in a neoclassical stochastic growth model, Journal of Economic Dynamics and Control, 25 (9), 1367-1397.

[12] Piketty, T., Saez, E., 2001. Income inequality in the United States, 19131998, NBER Working Paper 8467.

[13] Quadrini, V., Ríos-Rull, V., 1997. Understanding the US distribution of wealth, Federal Reserve Bank of Minneapolis Quarterly Review 21, $22-36$.

[14] Shorack, G.R., Wellner, J.A., 1986. Empirical Processes with Applications to Statistics, Wiley, New York, Chapter 2.

[15] White, H., 1980. A heterogeneity-consistent covariance matrix estimator and a direct test for heteroscedasticity, Econometrica 48, 817-838.

[16] White, H., 1982. Maximum likelihood estimation of misspecified models, Econometrica 50, 1-25. 


\section{Appendices}

In Appendix A, we provide the proofs to Propositions 2, 3, 4 in the main text. In Appendix B, we describe the data used for empirical study.

\subsection{Appendix A}

Proof of Proposition 2 The first-order condition of the individual problem (1), (2) with respect to hours worked is

$$
\frac{\mu e^{s} w_{t}}{c_{t}^{s}}=\frac{1-\mu}{1-n_{t}^{s}}
$$

By substituting (29) in the recursive constraint (8), we get

$$
z_{t}^{s} k_{t+1}=E_{t}\left[\sum_{\tau=t+1}^{\infty} \delta^{\tau-t} \frac{u_{1}\left(c_{\tau}, h_{\tau}\right)}{u_{1}\left(c_{t}, h_{t}\right)}\left(\frac{c_{\tau}^{s}}{\mu}-e^{s} w_{\tau}\right)\right]
$$

By using the formula for $c_{\tau}^{s}$ in (7), we can write

$$
z_{t}^{s} k_{t+1}=E_{t}\left[\sum_{\tau=t+1}^{\infty} \delta^{\tau-t} \frac{u_{1}\left(c_{\tau}, h_{\tau}\right)}{u_{1}\left(c_{t}, h_{t}\right)}\left(\frac{c_{\tau}}{\mu}\left(f^{s}-e^{s}\right)+\left(\frac{c_{\tau}}{\mu}-w_{\tau}\right) e^{s}\right)\right] .
$$

Summing the above expression over the set of agents yields

$$
k_{t+1}=E_{t}\left[\sum_{\tau=t+1}^{\infty} \delta^{\tau-t} \frac{u_{1}\left(c_{\tau}, h_{\tau}\right)}{u_{1}\left(c_{t}, h_{t}\right)}\left(\frac{c_{\tau}}{\mu}-w_{\tau}\right)\right] .
$$

After combining (31) and (32), we have

$$
z_{t}^{s}=e^{s}+\frac{\left(f^{s}-e^{s}\right)}{k_{t+1}} E_{t}\left[\sum_{\tau=t+1}^{\infty} \delta^{\tau-t} \frac{u_{1}\left(c_{\tau}, h_{\tau}\right)}{u_{1}\left(c_{t}, h_{t}\right)} \frac{c_{\tau}}{\mu}\right] .
$$

As condition (33) is to be satisfied for all $t$, we can write the same condition for some period $v \neq t$. By combining (33) written for $t$ and $v$, we can eliminate the term $\left(f^{s}-e^{s}\right)$. This gives us equations (10) and (11) in the main text. 
Proof of Proposition 3 Under the Cobb-Douglas production function, the individual income share, $y_{t}^{s}$, is described by equation (19). According to (10), the individual wealth share at $t-1$ is

$$
z_{t-1}^{s}=\xi_{t-1, v} z_{v}^{s}+\left(1-\xi_{t-1, v}\right) e^{s} .
$$

Expressing $f^{s}$ from the recursive constraint (33), written for $t=v$, and substituting it into the formula for $n_{t}^{s}$ in (7) yields

$$
n_{t}^{s}=h_{t}+\frac{\left(h_{t}-1\right) \mu\left(z_{v}^{s}-e^{s}\right) k_{v+1}}{e^{s} E_{v}\left[\sum_{\tau=v+1}^{\infty} \delta^{\tau-v} \frac{u_{1}\left(c_{\tau}, h_{\tau}\right)}{u_{1}\left(c_{v}, h_{v}\right)} c_{\tau}\right]}
$$

By substituting (34) and (35) into (19), we obtain equations (16) and (17).

Proof of Proposition 4 Differentiating the formula for $n_{t}^{s}$ in (7) with respect to $\theta_{t}$, we obtain

$$
\frac{\partial n_{t}^{s}}{\partial \theta_{t}}=\frac{\partial h_{t}}{\partial \theta_{t}} \frac{f^{s}}{e^{s}}
$$

According to (33), $f^{s}$ lies between agent's skill share, $e^{s}$, and her wealth share, $z_{t-1}^{s}$, i.e., $e^{s} \gtreqless f^{s} \gtreqless z_{t-1}^{s}$ when $e^{s} \gtreqless z_{t-1}^{s}$. This fact together with formula (36) implies results (21) and (22).

\subsection{Appendix B}

The variables we take from the PSID are as follows: the yearly household money income, $Y_{t}^{s}$; the yearly working hours of the head, $N_{t}^{s}$; the average hourly wage of the head, $W_{t}^{s}$; and the household wealth in 1984 and 1989, $Z_{1984}^{s}$ and $Z_{1989}^{s}$, respectively.

To construct the series for labor input, $h_{t}$, we first compute $H_{t}=\frac{\sum_{s=1}^{S_{t}} W_{t}^{s} N_{t}^{s}}{S_{t} \sum_{s=1}^{S_{t}} W_{t}^{s}}$, where $S_{t}$ denotes the number of observations in the PSID cross-section in year $t$. Given that the average share of time spent working in the U.S. is estimated to be 0.31 (see Juster and Stafford, 1991), we define $h_{t}$ by normalizing the mean of the time-series for $H_{t}$ correspondingly, i.e., $h_{t} \equiv \frac{0.31 H_{t}}{\sum_{t=1967}^{1991} H_{t}}$.

We construct the series for output, consumption and investment by using the data provided by the U.S. Department of Labor and the U.S. Department of Commerce (available from the website of the Federal Reserve Bank 
of Saint-Louis). Output, $y_{t}$, is defined as real GNP. Consumption, $c_{t}$, includes real personal expenditure on non-durables and services. Investment, $i_{t}$, is real personal consumption of durables and real fixed private investment. We convert the series for output, consumption and investment in per-capita terms.

We compute the series for the capital stock to match the data on investment. We specifically estimate the Cobb-Douglas production function, $y_{t}=\theta_{t} k_{t}^{\alpha} h_{t}^{1-\alpha}$ jointly with the capital accumulation equation,

$$
k_{t+1}=(1-\delta) k_{t}+i_{t}
$$

The estimation is carried out by maximum likelihood assuming a Gaussian $A R(1)$ process for $\log \left(\theta_{t}\right)$. 